\title{
Bioactive Membranes from Cellulose with a Graphene Oxide Admixture
}

\author{
Alicja Machnickaa ${ }^{1 *}$, Beata Fryczkowska² \\ 1 Institute of Environmental Protection and Engineering, University of Bielsko-Biała, ul. Willowa 2, \\ 43-309 Bielsko-Biała, Poland \\ 2 Institute of Textile Engineering and Polymer Materials, University of Bielsko-Biała, ul. Willowa 2, \\ 43-309 Bielsko-Biała, Poland \\ * Corresponding author's e-mail: amachnicka@ath.bielsko.pl
}

\begin{abstract}
The paper presents the results of microbiological tests of composite membranes made of cellulose (CEL) with graphene oxide (GO) admixture. At the beginning, the antibacterial properties of the $\mathrm{GO}$ in aqueous solutions of various concentrations $(0.001 ; 0.01 ; 0.1 \% \mathrm{w} / \mathrm{w})$ were studied, and the obtained results allowed to use GO as an additive to cellulose membranes. The solution used to prepare the membranes was a $5 \%$ cellulose solution (CEL) in 1-ethyl-3-methylimidazolium acetate (EMIMAc), into which various amounts of graphene oxide (GO) dispersed in N,N-dimethylformamide (DMF) were added $(0.5 \div 28.6 \%$ of GO). From this solution, composite membranes were formed using phase inversion method. It was observed that the GO addition influences the process of membrane formation and their physicochemical properties. The obtained membranes were subjected to microbiological tests using the Gram-negative bacteria (Escherichia coli), Gram-positive bacteria (Staphylococcuc aureus) and fungi (Candida albicans). It was observed that the GO addition to the cellulose membrane (GO/CEL) inhibited-the growth of bacteria and fungi, and the biological activity as dependent on the type of living organism and the size of GO particles.
\end{abstract}

Keywords: cellulose, graphene oxide, membranes, bactericidal properties, fungicidal properties

\section{INTRODUCTION}

Cellulose is one of the most widespread, inexpensive and biodegradable polymers, which is widely used in many industries [Ramamoorthy et al 2015, Yang et al. 2016]. Chemically, this polysaccharide is a polymer in which the chains of cellulose are linked with hydrogen bonds (intramolecular and intermolecular), which hinder the dissolution of this biopolymer in classical solvents [Fink et al. 2001, Lindman et al. 2010].

An interesting group of solvents which dissolve polysaccharides are ionic liquids, which due to their biodegradability and low toxicity [Novoselov et al. 2007, Pinkert et al. 2009, Zhu et al. 2006] are called "green" solvents. Cellulose dissolved in ionic liquids can be precipitated with polar solvents to obtain "flocs," fibres or membranes [Kuo \& Hong 2005, Rambo et al. 2008].

Graphene oxide (GO) is a modern material, which due to the presence of oxygen groups (epoxide, hydroxyl, carbonyl, carboxyl) [GuerreroContreras \& Caballero-Briones 2015] shows hydrophilic properties. GO can be easily dispersed both in water [Texter 2014, Yoon et al. 2013] and in classic organic solvents such as N,Ndimethylformamide (DMF), N-methyl-2-pyrrolidone, tetrahydrofuran and ethylene glycol [Parades et al. 2008].

Graphene oxide is used as a component of composite materials. Combining GO with cellulose, a hydrophilic composite can be obtained. Zhang et al. (2015) described the method to obtain GO-containing microbeads in $\mathrm{NaOH}$ and 
urea solution, by coagulation in mineral acid. Aerogels were obtained from bamboo fibres dissolved in a $\mathrm{NaOH} /$ polyethylene glycol (PEG) mixture to which water-dispersed GO was added [Wan \& Li 2016]. The hydrogels were prepared from an aqueous dispersion of $\mathrm{GO}, \mathrm{NaOH}$ and urea and cellulose, which were combined with a polyvinyl alcohol (PVA) solution [Rui-Hong et al. 2016]. Liu et al. (2016) obtained cellulose composite membranes in the simplest way possible - by filtration of GO solution on pure cellulose membrane. The paper-making method was used to obtain paper from cellulose, with GO and polyacrylamide addition [Huang et al. 2016] or by mixing the suspension of hydrolysed microcrystalline cellulose with a GO dispersion [Kafy et al. 2016]. Kim et al. (2011), on the other hand, obtained a membrane by dissolving GO and cellulose in $\mathrm{N}$-methylmorpholine $\mathrm{N}$-oxide (NMMO). Tang et al. (2012) received composite membranes using a layer-by-layer (LbL) method. For this purpose, a cellulose solution in an ionic liquid 1-butyl-3-methylimidazolium chloride $([\mathrm{Bmim}] \mathrm{Cl})$ was applied to the glass plate, dried and then coated with a GO dispersion. Yang et al. (2016) mixed the grinded bacterial cellulose with GO dispersion and formed a composite film. Another research team obtained GO/CEL composite granulate during cellulose synthesis by Acetobacter xylinum [Zhu et al. 2015]. The team of Luo used the Komagataebolacter xylinus X-2 bacteria to which a suspension of GO was added, for the synthesis of the hydrogel [Luo et al. 2017].

Graphene oxide also has bactericidal properties, both for Gram-positive and Gram-negative bacteria such as Escherichia coli (E. coli) [Liu et al. 2012, Tu et al. 2013], Pseudomonas aerugino$s a$ [Shahnawaz Khan et al. 2015, Singh \& Singh, 2017], Staphylococcus aureus (S. aureus) [Akhavan \& Ghaderi 2010, Liu et al. 2017, Singh 2016], Bacillius subtilis [Musico et al. 2014]. In addition, studies of GO fungicidal properties against Candida utilis and Saccharomyces cerevisiae [Shahnawaz Khan et al. 2015] as well as Mucor racemosus [Li et al. 2017] were also carried out.

GO's bactericidal properties in combination with other materials allowed to obtain products that could be used as packaging [Hu et al. 2010], pharmaceutical carriers [Luo et al. 2017], scaffolds [Kanayama et al. 2014, Mahmoudi et al., 2017, Pal et al. 2017]. Owing to its biocidal properties, GO can be used to design membranes not susceptible to biofouling. Yang et al. (2018) described a method for obtaining membranes of enhanced biofouling resistance, by creating a GO laminate with silver nanoparticle and polydopamine. These membranes can be used for water treatment and ion separation. Lim et al. (2017) developed antibacterial graphene oxide membranes functionalised with acid and polyethyleneimine, which can be used for ion separation. Other researchers have obtained biofouling resistant membranes based on cellulose acetate coated with graphene oxide-silver nanoparticles [Sun et al. 2015]. Musico et al. (2014) used the modification of commercial membranes using poly $(\mathrm{N}-$ vinylcarbazole)-graphene oxide to obtain antibacterial membranes that can be used for treating water and wastewater.

This paper presents the results of bactericidal properties of graphene oxide (obtained from graphite with two different particle sizes $<20 \mu \mathrm{m}$ and $<150 \mu \mathrm{m})$ and the effect of the concentration of these nanoparticles and their size on the growth of E. coli and S. aureus bacteria. GO with the best bactericidal properties was used to prepare cellulose membranes with graphene oxide addition. 1-ethyl-3-methylimidazole acetate (EMIMAc) was used to prepare the cellulose solution. GO was dispersed in DMF. Composite membranes were prepared from a homogenous CEL/EMIMAc and GO/DMF solutions by phase inversion and then subjected to microbiological tests. E. coli and S. aureus bacteria as well as Candida albicans fungus were used for testing the membranes. It was observed that the bactericidal and fungicidal properties of membranes depend on the type of microorganism and the concentration of GO in the sample.

\section{MATERIALS AND TEST METHODS}

\section{Reagents}

Cellulose (long fibres), ionic fluid: 1-ethyl3-methylimidazolium acetate (EMIMAc), graphite powder $<20 \mu \mathrm{m}$ and graphite $<150 \mu \mathrm{m}$, were purchased from Sigma-Aldrich. $\mathrm{NaNO}_{3}, 98 \%$ $\mathrm{H}_{2} \mathrm{SO}_{4}, \mathrm{KMnO}_{4}, 30 \% \mathrm{H}_{2} \mathrm{O}_{2}, \mathrm{~N}, \mathrm{~N}$-dimetyloformamide (DMF), $\mathrm{NaCl}$ were purchased from Avantor Performance Materials Poland S.A. The Staphylococcus aureus (ATCC 33741-B1), Escherichia coli (ATCC 35925-B2), and Candida albicans (ATCC BAA-473) were purchased from ATCC (American Type Culture Collection). 
Blood agar, Chapman medium, MacConkey medium, Candida agar were purchased from BTL Ltd. Department of enzymes and peptones, Łódź.

\section{Graphene oxide}

Graphene oxide was obtained according to modified Hummers method [Hummers \& Offeman 1958], described in our previous paper [Fryczkowska et al. 2015].

At the beginning, $1 \mathrm{~g}$ of $\mathrm{NaNO}_{3}$ and $46 \mathrm{~cm}^{3}$ of $\mathrm{H}_{2} \mathrm{SO}_{4}$ and $2 \mathrm{~g}$ of graphite powder were placed in the flask in ice bath. The reaction mixture was stirred intensively for 30 minutes until the temperature was reduced to approx. $5^{\circ} \mathrm{C}$. Thereafter, $6 \mathrm{~g}$ of $\mathrm{KMnO}_{4}$ was slowly added in portions, taking care to prevent the exothermic reaction not to increase the temperature above $20^{\circ} \mathrm{C}$. After the entire $\mathrm{KMnO}_{4}$ was added, stirring was continued for another 5 minutes, after which the reaction mixture was warmed to $35{ }^{\circ} \mathrm{C}$. Stirring was continued for $4 \mathrm{~h}$, after which $92 \mathrm{~cm}^{3}$ of distilled water was slowly added to dilute the acid. Excess $\mathrm{KMnO}_{4}$ was removed by introducing a solution containing: $80 \mathrm{~cm}^{3}$ of distilled water and $50 \mathrm{~cm}^{3}$ of $3 \% \mathrm{H}_{2} \mathrm{O}_{2}$. Finally, the graphene oxide obtained in the reaction was centrifuged and washed several times with distilled water until $\mathrm{pH} 7$. Wet graphene oxide was dried in a drying oven at $60{ }^{\circ} \mathrm{C}$ turning into a brown-coloured solid.

The synthesis of graphene oxide was carried out for two types of graphite: graphite powder $<20 \mu \mathrm{m}$, obtaining GO1 and graphite with grain size $<150 \mu \mathrm{m}$, obtaining GO2.

Then in the volumetric flasks, solutions of GO1 and GO2 in distilled water were prepared with concentrations of: $0.001 ; 0.01 ; 0.1 \%$.

\section{GO/CEL composite membranes}

The membrane-forming solutions were prepared as described in our earlier article [Fryczkowska \& Wiechniak 2017]. Initially, a 5\% solution of cellulose in the ionic fluid - 1-ethyl- 3-methylimidazolium acetate (EMIMAc) was prepared. The mixture of cellulose and EMIMAc was thoroughly mixed and then heated in a laboratory microwave oven, taking care that the temperature of the mixture did not exceed approx. $40{ }^{\circ} \mathrm{C}$. The resulting cellulose solutions were left for 24 hours to deaerate.

In order to prepare solutions for forming $\mathrm{GO} / \mathrm{CEL}$ composite membranes, adequate amounts of cellulose and ionic fluid were first weighed (Table 1) and cellulose solutions were prepared as described above. Then, a GO1 dispersion was prepared. To do this, dry GO1 was dispersed in DMF in an ultrasonic bath, resulting in a dispersion with a concentration of $3.7 \% \mathrm{GO} 1 / \mathrm{DMF}$.

The appropriate amounts of GO1/DMF dispersion were then added to the cellulose solutions (Table 1) and mixed intensively using a laboratory stirrer for 1 week.

Cellulose membranes were prepared using wet phase inversion method. For this purpose, the cellulose-forming solution was poured onto a leveled, clean glass plate. Then, a polymer film was formed using casting knife with an adjustable thickness fixed at $0.2 \mathrm{~mm}$ and coagulated in distilled water. The precipitated membranes were dried.

As a result of the experiment, a pure cellulose membrane ("0") and composite GO1/CEL cellulose membranes with different amounts of GO (A, B, C, D, E, F) were obtained. The physicochemical properties of the membranes were described in an earlier publication (Fryczkowska \& Wiechniak 2017).

\section{Microbiological analysis}

The samples were exposed to bacteria and fungi capable of causing infections in humans, i.e. the Gram-positive Staphylococcus aureus and Gram-negative Escherichia coli, and Candi$d a$ albicans. The microorganisms were growing on blood agar. Microorganisms were incubated

Table 1. The composition of solutions to prepare the membranes

\begin{tabular}{|l|c|c|c|c|c|c|c|}
\hline \multicolumn{1}{|c|}{ Membrane designation } & „0" & $\mathrm{A}$ & $\mathrm{B}$ & $\mathrm{C}$ & $\mathrm{D}$ & $\mathrm{E}$ & $\mathrm{F}$ \\
\hline The amount of 3.7\% GO/DMF solution [g] & 0 & 0.135 & 0.34 & 0.67 & 1.35 & 6.76 & 13.5 \\
\hline The amount of CEL [g] & 2.5 & 2.5 & 2.5 & 2.5 & 2.5 & 2.5 & 2.5 \\
\hline The amount of EMIMAC [g] & 47.5 & 47.4 & 47.2 & 46.8 & 46.2 & 40.1 & 34.0 \\
\hline W/w conc. of GO1 [\%] & 0 & 0.5 & 1.0 & 2.0 & 3.8 & 16.7 & 28.6 \\
\hline W/w conc. of CEL [\%] & 100 & 99.5 & 99.0 & 98.0 & 96.2 & 83.3 & 71.4 \\
\hline
\end{tabular}


at $36 \pm 2{ }^{\circ} \mathrm{C}$, for 24 hours. Grown cultures were washed out with $1 \mathrm{ml}$ of physiological salt solution, and $0,1 \mathrm{ml}$ added to the sterile selective agar. The following mediums for cultivation of microorganisms were used: Chapman agar $-S$. aureus, MacConkey agar - E.coli and Candida agar Candida albicans. Seeding of "grated tiles" was using. A samples were placed in the centre of the Petri plate. The Petri plates with samples were subsequently placed into a laboratory heater and then kept heated at $36 \pm 2^{\circ} \mathrm{C}$ for 24 hours. Sterile paper discs (diameter $1.0 \mathrm{~cm}$ ) impregnated (two drops) with GO solution (graphene oxide - 0.001; $0.01 ; 0.1 \% \mathrm{w} / \mathrm{w}$ ) and composite membranes GO1/CEL were samples for testing. The cellulose foils were of a size 1 x $1 \mathrm{~cm}$. A control samples (cellulose foil - membrane " 0 "). were done. The experiment was performed three times for each sample of membrane. Growth inhibition zones were read by stereoscopic microscope equipped with Olympus CCD ARTCAM camera.

\section{RESULTS AND ANALYSIS}

\section{GO characterization}

Graphene oxide, which was used to obtain composite GO1/CEL membranes, was studied using X-ray diffraction, DSC thermal gravimetric analysis and FTIR spectroscopy. The obtained results were similar to the results described in our earlier work [Fryczkowska et al., 2015].

\section{Bactericidal properties of the aqueous GO solution}

The GO obtained from graphite with different particle size was used to study the antimicrobial properties of graphene oxide, resulting in GO1 with an area $<20 \mu \mathrm{m}$ and GO2 with an area $<120 \mu \mathrm{m}$.

Studies shown that GO1 had bactericidal properties against $E$. coli, regardless of the graphene oxide concentration. In all cases, a marked inhibition of the growth of this bacteria was observed. For cellulose discs with a diameter of $1 \mathrm{~cm}$, the width of the inhibition zone was $\sim 2 \mathrm{~mm}$ (Fig. 1). S. aureus, on the other hand, is more resistant to the GO1 particles dispersion. The highest rate of bacterial growth inhibition was observed for the highest concentration of graphene oxide $(0.1 \% \mathrm{w} / \mathrm{w})$ and it was $\sim 0.5 \mathrm{~mm}$ wide. For lower concentrations of GO1 (0.01 and $0.001 \%$ w/w) it was observed that the $S$. aureus growth inhibition width zone was even smaller: $\sim 0.2$ and $\sim 0.1 \mathrm{~mm}$ (Fig. 1).

When conducting microbiological tests using $\mathrm{GO} 2$, it was observed that $S$. aureus is completely resistant to large flakes of graphene oxide. Regardless of the concentration of nanoparticles in the aqueous solution, no zones of $S$. aureus growth inhibition were observed (Fig. 2). However, studies conducted on E. coli shown that the GO2 bactericidal properties depend on the concentration of graphene oxide in the aqueous solution. At the highest concentration of GO2 $(0.1 \% \mathrm{w} / \mathrm{w})$, the largest zone of inhibition of $\sim 2 \mathrm{~mm}$ was recorded.

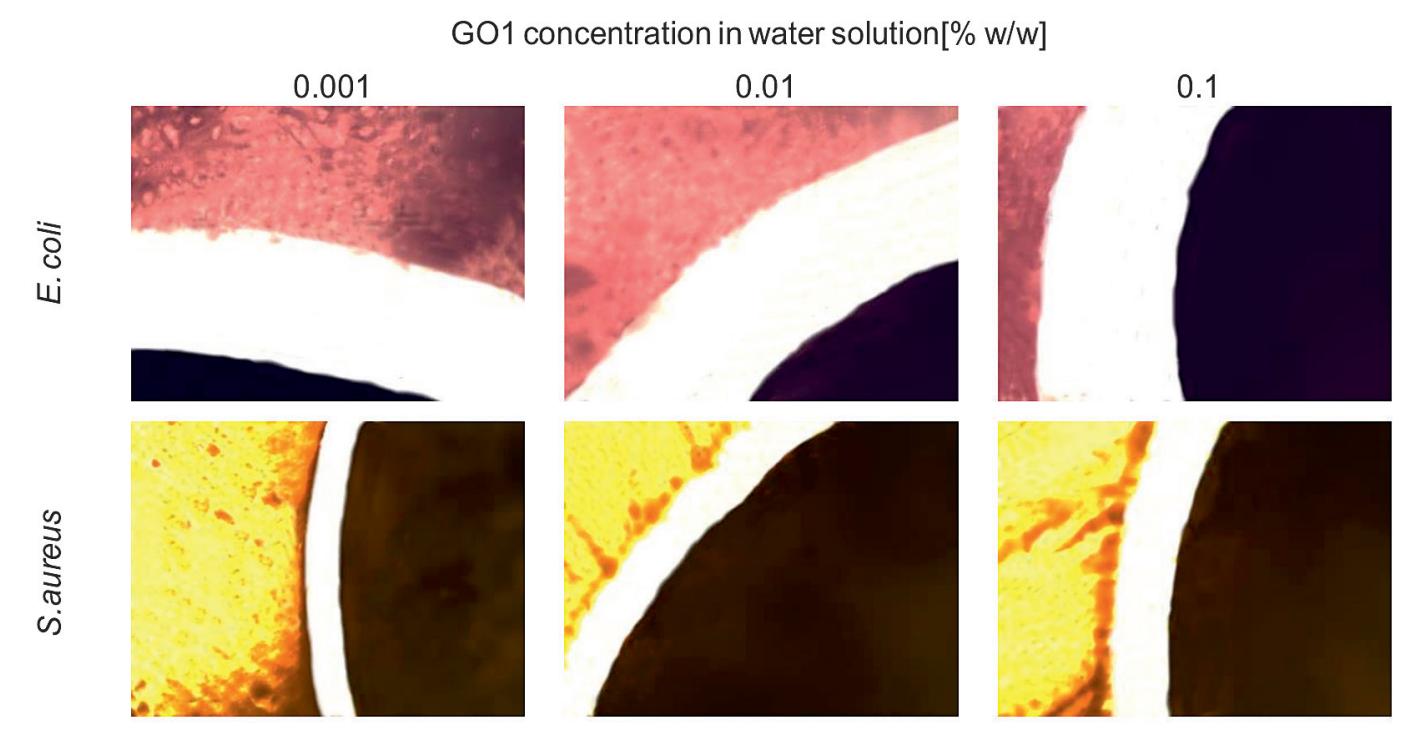

Fig. 1. Microphotographs of cellulose discs (dark box) impregnated with a GO1 solution after $24 \mathrm{~h}$ incubation of E. coli and $S$. aureus 


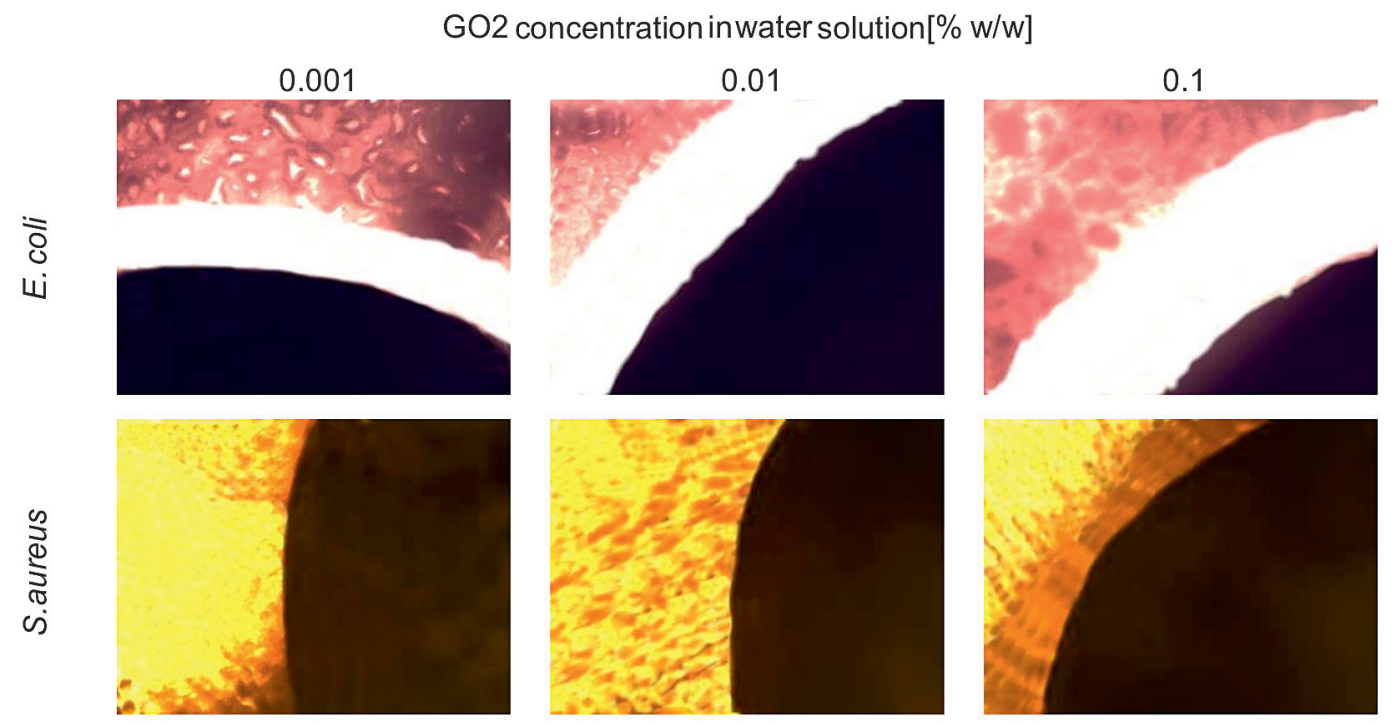

Fig. 2. Microphotographs of cellulose discs (dark box) impregnated with a GO2 solution after $24 \mathrm{~h}$ incubation of E. coli and S. aureus

Then, along with the decrease in GO2 concentration, the $E$. coli inhibition zones were decreased, successively, to $\sim 1.5 \mathrm{~mm}$ for $0.01 \% \mathrm{w} / \mathrm{w}$ of GO and to $\sim 1.0 \mathrm{~mm}$ for $0.001 \% \mathrm{w} / \mathrm{w} \mathrm{GO} 2$ (Fig. 2).

Analysing the results of the experiment, it was observed that $E$. coli, which belongs to the Gram negative bacteria, was less resistant to GO molecules in aqueous solution (Fig. 3). In the case of GO1 particles with a size of $<20 \mu \mathrm{m}$, the growth of small cells of bacteria $(2 \times 0.8 \mu \mathrm{m})$ were inhibited, which results in a relatively large area of E. coli growth inhibition observed in the pictures. One of the reasons could be breaking of the thin cell membrane, resulting in a leakage of cytoplasm, as described in the literature [Palmieri et al. 2017].

In the studies conducted on GO2 solutions, it was observed that strong bactericidal properties were observed in solutions with a high $(0.1 \% \mathrm{w} / \mathrm{w})$ concentration of GO2 (Fig. 3). Comparing the size of the $E$. coli cell to the size of GO2 particles, one can suspect a different mechanism of stopping the growth of these bacteria. In this case, one may assume that we are dealing with the wrapping and/or trapping of bacteria, as described in the literature [Palmieri et al. 2017], resulting in membrane stress and/or oxidative stress, leading to the bacteria death.

Gram positive $S$. aureus has a spherical shape. Its size is $0.8 \div 1 \mu \mathrm{m}$ and has a thick, single-layer cell wall, which makes it difficult for external factors to penetrate the interior of the bacteria. The size and structure of the bacteria makes it completely resistant to large GO2 molecules (Fig. 3).
On the other hand, in the case of GO1, it was observed, that the toxicity of graphene oxide increases with its concentration in solution. The observed phenomenon could be explained by the fact that in low concentration solutions the probability of encountering the GO1 particle and damage to the bacterial cell wall was smaller than in high concentration solutions. Therefore it could be assumed that the destruction of $S$. aureus occurs as a result of cutting the membrane and leakage of cytoplasm [Palmieri et al. 2017].

\section{Bactericidal and fungicidal properties of $\mathrm{GO}$ / CEL membranes}

Microbiological investigations for pure cellulose membrane ("0") and GO/CEL membranes were carried out with $E$. coli, S. aureus bacteria and additionally with Candida albicans fungi.

GO/CEL composite membranes have bactericidal properties against $E$. coli both for low and high concentrations of nanopowder in the membrane (Fig. 4). The largest area of growth inhibition of $0.43 \mathrm{~mm}$ wide for $1 \times 1 \mathrm{~cm}$ samples was observed for membrane A $(0.5 \% \mathrm{w} / \mathrm{w}$ of GO1), what indicated the bioavailability of GO1 in membrane A. The use of GO1 admixture in the amount of $1 \% \mathrm{w} / \mathrm{w}$ or more (Table 1 ) resulted in an initial decrease in the bacterial inhibition zone from a width of $0.16 \mathrm{~mm}$ for membrane $\mathrm{B}$, through $0.24 ; 0.25 ; 0.29 ; 0.31 \mathrm{~mm}$ for $\mathrm{C}, \mathrm{D}, \mathrm{E}$ and F membranes, respectively. The obtained results allowed to conclude, that a fairly good resistance to $E$. coli was ensured by the lowest GO1 addi- 


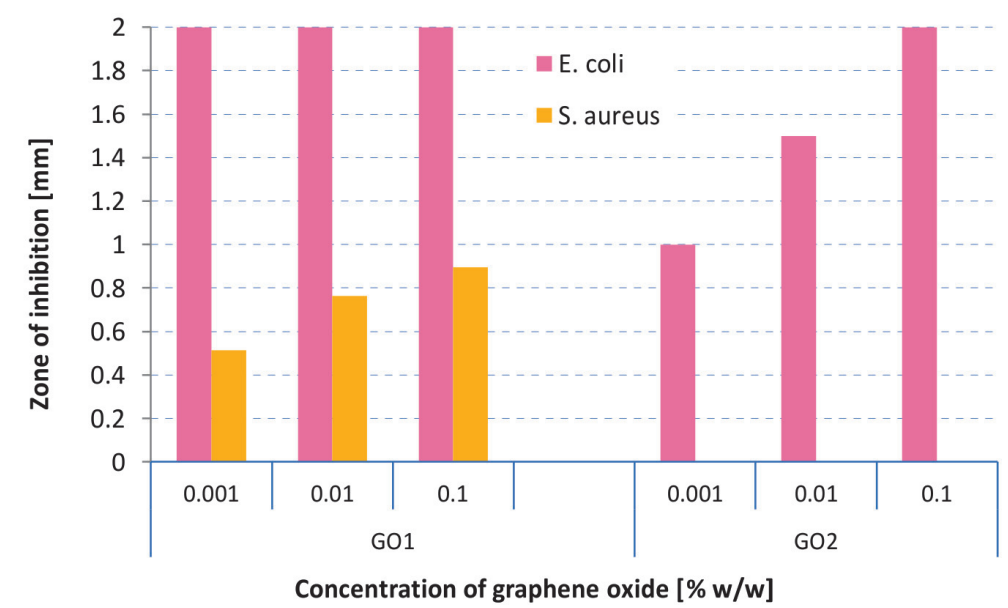

Fig. 3. Zone of bacterial growth inhibition (of E. coli and S. aureus) around cellulose discs impregnated with GO1 and GO2 solutions of appropriate concentrations

tion in the GO/CEL composite membranes. The introduction of graphene oxide above $0.5 \% \mathrm{w} / \mathrm{w}$ into composite cellulose membranes did not significantly improve the antibacterial properties of these membranes against E. coli.

Other results were obtained for membrane studies using S. aureus (Fig. 4). Analysis of the obtained results showed that this bacteria was resistant to low concentrations of GO1 in composite membranes A and $\mathrm{B}$. The largest inhibition zone was observed for membrane $\mathrm{C}-\mathrm{a}$ width of $0.81 \mathrm{~mm}$. In the case of consecutive membranes, this zones were: $0.57 ; 0.34 ; 0.23 \mathrm{~mm}$ wide for membranes D, E and F, repectively.

The obtained results with Candida albicans fungus clearly indicated that GO1 assured the fungicidal properties of GO/CEL composite membranes (Fig. 4). The fungicidal effect of the membranes was directly related to the concentration of graphene oxide in the membrane. The higher the concentration of GO1, the more resistant to the fungi it was. For membrane A, a $0.1 \mathrm{~mm}$ width of growth inhibition was observed. The following membranes had increasingly wider growth inhibition zones, starting from $0.14 ; 0.18 ; 0.25 ; 0.32$ mm width for membranes B, C, D, E. The highest concentration of GO1 was for membrane $\mathrm{F}(28.6 \%$ $\mathrm{w} / \mathrm{w})$, and this membrane had the highest growth inhibition area for Candida albicans of $0.48 \mathrm{~mm}$.

Adding GO1 to cellulose membrane "0" makes it resistant to selected bacteria and fungi (Fig. 5). Graphene oxide, as an additive to a cellulose-based composite, gave bactericidal properties against Gram negative E. coli and fungicidal properties against Candida albicans. It should also be noted that an admixture of graphene oxide in the cellulose membrane as low as $0.5 \% \mathrm{w} / \mathrm{w}$ increased its resistance to microorganisms.

In the case of Gram positive $S$. aureus, the biocidal action occured only above $2 \% \mathrm{w} / \mathrm{w}$ of GO addition to the cellulose matrix. Membrane $\mathrm{C}$ had a very good bactericidal action against $S$. aureus, almost 2 times higher than the highest value obtained for E. coli and Candida albicans. The remaining membranes (D, E, F) were characterized by antibacterial action at the level similar to E. coli.

Comparison the bactericidal and fungicidal action of graphene oxide in the GO/CEL membranes prepared by us with the results described in the literature is difficult. The biological activity of a GO-containing composite depends on many factors, including the method of obtaining the composite, the size and degree of dispersion of the nanoaddition particles, and the microbiological availability of the bioactive components.

\section{CONCLUSIONS}

This paper presented the results of research on bioactive membranes made of cellulose (CEL) with graphene oxide (GO) admixture. The studies on the biocidal properties of the membranes were preceded with GO as the modifier. At the beginning, the influence of the size of nanoparticles and their concentration on the growth of $E$. coli and $S$. aureus were examined. For this purpose, graphene oxide was obtained from graphite with two different particle sizes, $<20 \mu \mathrm{m}$ and $<150 \mu \mathrm{m}$, as a result of which GO1 and GO2 were formed. Both products were dispersed in water to con- 

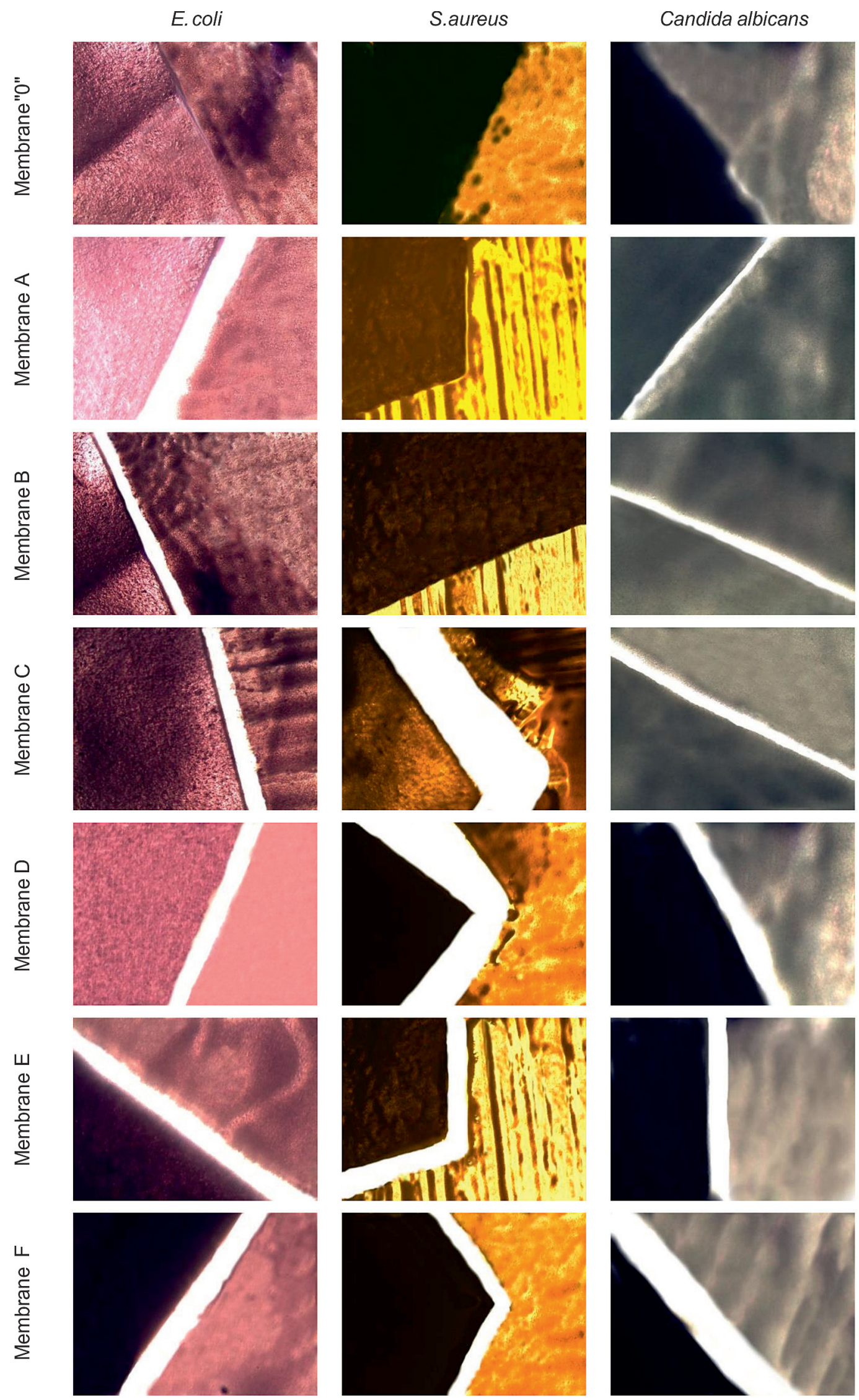

Fig. 4. Microscope photos of growth inhibition zones around cellulose membranes ("0") and GO/CEL composite membranes after 24 hours of incubation of E. coli, S. aureus and Candida albicans fungi 


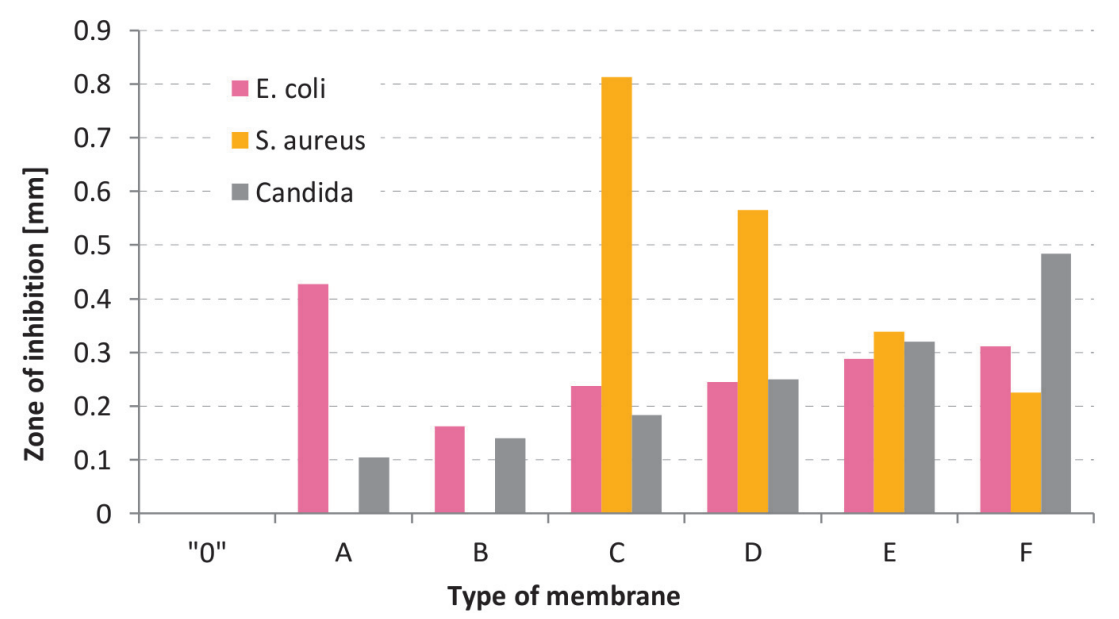

Fig. 5. Zones of bacterial (of E. coli and $S$. aureus) and Candida albicans fungi growth inhibition around the cellulose membrane (membrane " 0 ") and GO/CEL composite membranes (membrane A $\div$ F)

centrations of $0.001 ; 0.01 ; 0.1 \% \mathrm{w} / \mathrm{w}$ of GO. It was observed that $E$. coli was less resistant to the GO1 molecules, and the area of growth inhibition for this bacteria was high, regardless of the concentration of graphene oxide in the sample. The tests carried out with GO2 solutions showed that the strong bactericidal action against $E$. coli is only with the highest GO concentration. Studies conducted with $S$. aureus showed complete resistance to GO2 but that small particles of GO1 showed the antibacterial action.

The obtained GO/CEL membranes were subjected to microbiological analysis in which E. coli and $\mathrm{S}$. aureus as well as Candida albicans fungi were used. The obtained results indicated that adding GO1 to GO/CEL cellulose membranes gave resistance to bacteria and fungus. Graphene oxide, introduced even in low concentrations $(0.5 \% \mathrm{w} / \mathrm{w})$ into the cellulose composite, gave bactericidal properties against $\mathrm{E}$. coli and fungicidal properties against Candida albicans. In the case of S. aureus, on the other hand, the biocidal action occured only above $2 \% \mathrm{w} / \mathrm{w}$ of GO addition to the cellulose matrix.

The results of our studies indicate that $\mathrm{GO} /$ CEL composite membranes obtained in the process of GO1 addition to cellulose have a bioactive effect, both for Gram-negative and Grampositive bacteria as well as fungi of Candida albicans. These properties enable the use of GO/CEL composite membranes as potential dressing and packaging materials. Graphene oxide enclosed in the structure of the GO/CEL membrane is not released into the environment, which allows its safe use, e.g. in membrane water treatment processes.

\section{REFERENCES}

1. Akhavan O., Ghaderi E. 2010. Toxicity of graphene and graphene oxide nanowalls against bacteria. ACS Nano, 4(10), 5731-5736.

2. Fink H. P., Weigel P., Purz H. J. Ganster J. 2001. Structure formation of regenerated cellulose materials from NMMO-solutions. Progress in Polymer Science (Oxford), 26(9), 1473-1524.

3. Fryczkowska B., Sieradzka M., Sarna E., Fryczkowski R., Janicki J. 2015. Influence of a graphene oxide additive and the conditions of membrane formation on the morphology and separative properties of poly(vinylidene fluoride) membranes. Journal of Applied Polymer Science, 132(46), 42789.

4. Fryczkowska B., Wiechniak K. 2017. Preparation and properties of cellulose membranes with graphene oxide addition. Polish Journal of Chemical Technology, 19(4), 41-49.

5. Guerrero-Contreras J., Caballero-Briones F. 2015. Graphene oxide powders with different oxidation degree, prepared by synthesis variations of the Hummers method. Materials Chemistry and Physics, 153, 209-220.

6. Hu W., Peng C., Luo W., Lv M., Li X., Li D., Huang Q, Fan C. 2010. Graphene-based antibacterial paper. ACS Nano, 4(7), 4317-4323.

7. Huang Q., Xu M., Sun R., Wang X. 2016. Large scale preparation of graphene oxide/cellulose paper with improved mechanical performance and gas barrier properties by conventional papermaking method. Industrial Crops and Products, 85, 198-203.

8. Hummers W. S., Offeman R. E. 1958. Preparation of Graphitic Oxide. Journal of the American Chemical Society, 80(6), 1339-1339.

9. Kafy A., Akther A., Shishir M. I. R., Kim H. C., Yun Y., Kim J. 2016. Cellulose nanocrystal/gra- 
phene oxide composite film as humidity sensor. Sensors and Actuators, A: Physical, 247, 221-226.

10. Kanayama I., Miyaji H., Takita H., Nishida E., Tsuji M., Fugetsu B., Sun L., Inoue K, Ibara A., Akasaka T., SugayaT., Kawanami M. 2014. Comparative study of bioactivity of collagen scaffolds coated with graphene oxide and reduced graphene oxide, 3363-3373.

11. Kim C. J., Khan W., Kim D. H., Cho K. S., Park S. Y. 2011. Graphene oxide/cellulose composite using NMMO monohydrate. Carbohydrate Polymers, 86(2), 903-909.

12. Kuo Y. N., Hong J. 2005. A new method for cellulose membrane fabrication and the determination of its characteristics. Journal of Colloid and Interface Science, 285(1), 232-238.

13. Li G., Zhao H., Hong J., Quan K., Yuan Q., Wang X. 2017. Antifungal graphene oxide-borneol composite. Colloids and Surfaces B: Biointerfaces, 160, 220-227.

14. Lim M. Y., Choi Y. S., Kim J., Kim K., Shin H., Kim J. J., Shin D.M., Lee J. C. 2017. Cross-linked graphene oxide membrane having high ion selectivity and antibacterial activity prepared using tannic acid-functionalized graphene oxide and polyethyleneimine. Journal of Membrane Science, 521, 1-9.

15. Lindman B., Karlström G., Stigsson L. 2010. On the mechanism of dissolution of cellulose. Journal of Molecular Liquids, 156(1), 76-81.

16. Liu G., Ye H., Li A., Zhu C., Jiang H., Liu Y., Han K., Zhou Y. 2016. Graphene oxide for high-efficiency separation membranes: Role of electrostatic interactions. Carbon, 110, 56-61.

17. Liu S., Hu M., Zeng T. H., Wu R., Jiang R., Wei J., Wang L., Kong J., Chen Y. 2012. Lateral Dimension-Dependent Antibacterial Activity of Graphene Oxide Sheets. Langmuir, 28(33), 12364-12372.

18. Liu Y., Wen J., Gao Y., Li T., Wang H., Yan H., Niu B., Guo R. 2017. Antibacterial graphene oxide coatings on polymer substrate. Applied Surface Science, (2010).

19. Luo H., Ao H., Li G., Li W., Xiong G., Zhu Y., Wan Y. 2017. Bacterial cellulose/graphene oxide nanocomposite as a novel drug delivery system. Current Applied Physics, 17(2), 249-254.

20. Mahmoudi N., Eslahi N., Mehdipour A., Mohammadi M., Akbari M., Samadikuchaksaraei A., Simchi A. 2017. Temporary skin grafts based on hybrid graphene oxide-natural biopolymer nanofibers as effective wound healing substitutes: pre-clinical and pathological studies in animal models. Journal of Materials Science: Materials in Medicine, 28(5), $1-12$.

21. Musico Y. L. F., Santos C. M., Dalida M. L. P., Rodrigues D. F. 2014. Surface Modification of Membrane Filters Using Graphene and Graphene
Oxide-Based Nanomaterials for Bacterial Inactivation and Removal. ACS Sustainable Chem. Eng, 2, 1559-1565.

22. Novoselov N. P., Sashina E. S., Kuz'mina O. G., Troshenkova S. V. 2007. Ionic liquids and their use for the dissolution of natural polymers. Russian Journal of General Chemistry, 77(8), 1395-1405.

23. Pal N., Dubey P., Gopinath P., Pal K. 2017. Combined effect of cellulose nanocrystal and reduced graphene oxide into poly-lactic acid matrix nanocomposite as a scaffold and its anti-bacterial activity. International Journal of Biological Macromolecules, 95, 94-105.

24. Palmieri V., Carmela Lauriola M., Ciasca G., Conti C., De Spirito M., Papi M. 2017. The graphene oxide contradictory effects against human pathogens. Nanotechnology, 28(15), 152001

25. Parades J. I., Villar-Rodil S., Martínez-Alonso A., Tascón J. M. D. 2008. Graphene oxide dispersions in organic solvents. Langmuir, 24(19), 1056010564.

26. Pinkert A., Marsh K. N., Pang S., Staiger M. P. 2009. Ionic liquids and their interaction with cellulose. Chemical Reviews, 109(12), 6712-6728.

27. Ramamoorthy S. K., Skrifvars M., Persson A. 2015. A Review of Natural Fibers Used in Biocomposites: Plant, Animal and Regenerated Cellulose Fibers. Polymer Reviews, 55(1), 107-162.

28. Rambo C. R., Recouvreux D. O. S., Carminatti C. A., Pitlovanciv A. K., Antônio R. V., Porto L. M. 2008. Template assisted synthesis of porous nanofibrous cellulose membranes for tissue engineering. Materials Science and Engineering C, 28(4), 549-554.

29. Rui-Hong X., Peng-Gang R., Jian H., Fang R., Lian-Zhen R., Zhen-Feng S. 2016. Preparation and properties of graphene oxide-regenerated cellulose/polyvinyl alcohol hydrogel with $\mathrm{pH}$-sensitive behavior. Carbohydrate Polymers, 138, 222-228.

30. Shahnawaz Khan M., Abdelhamid H. N., Wu H. F. 2015. Near infrared (NIR) laser mediated surface activation of graphene oxide nanoflakes for efficient antibacterial, antifungal and wound healing treatment. Colloids and Surfaces B: Biointerfaces, 127, 281-291.

31. Singh Z. 2016. Applications and toxicity of graphene family nanomaterials and their composites. Nanotechnology, Science and Applications, 9, 15-28.

32. Singh Z., Singh R. 2017. Toxicity of Graphene Based Nanomaterials Towards Different Bacterial Strains: A Comprehensive Review. American Journal of Life Sciences American Journal of Life Sciences. Special Issue: Environmental Toxicology, 5(5), 3-1.

33. Sun X. F., Qin J., Xia P. F., Guo B. B., Yang C. M., Song C., Wang S. G. 2015. Graphene oxide-silver 
nanoparticle membrane for biofouling control and water purification. Chemical Engineering Journal, 281, 53-59.

34. Tang L., Li X., Du D., He C. 2012. Fabrication of multilayer films from regenerated cellulose and graphene oxide through layer-by-layer assembly. Progress in Natural Science: Materials International, 22(4), 341-346.

35. Texter J. 2014. Graphene dispersions. Current Opinion in Colloid and Interface Science. 19(2), 163-174.

36. Tu Y., Lv M., Xiu P., Huynh T., Zhang M., Castelli M., Liu Z., Huang Q., Fan C., Fang H., Zhou R. 2013. Destructive extraction of phospholipids from Escherichia coli membranes by graphene nanosheets. Nature Nanotechnology, 8(8), 594-601.

37. Wan C., Li J. 2016. Graphene oxide/cellulose aerogels nanocomposite: Preparation, pyrolysis, and application for electromagnetic interference shielding. Carbohydrate Polymers, 150, 172-179.

38. Yang E., Alayande A. B., Kim C.-M., Song J., Kim I. S. 2018. Laminar reduced graphene oxide membrane modified with silver nanoparticle-polydopamine for water/ion separation and biofouling resistance enhancement. Desalination, 426(October 2017).
39. Yang X. N., Xue D. D., Li J. Y., Liu M., Jia S. R., Chu L. Q., Wahid F., Zhang Y. M., Zhong C. 2016. Improvement of antimicrobial activity of graphene oxide/bacterial cellulose nanocomposites through the electrostatic modification. Carbohydrate Polymers, 136, 1152-1160.

40. Yoon K. Y., An S. J., Chen Y., Lee J. H., Bryant S. L., Ruoff R. S., Huh C., Johnston K. P. 2013. Graphene oxide nanoplatelet dispersions in concentrated $\mathrm{NaCl}$ and stabilization of oil/water emulsions. Journal of Colloid and Interface Science, 403, 1-6.

41. Zhang X., Yu H., Yang H., Wan Y., Hu H., Zhai Z., Qin J. 2015. Graphene oxide caged in cellulose microbeads for removal of malachite green dye from aqueous solution. Journal of Colloid and Interface Science, 437, 277-282.

42. Zhu S., Wu Y., Chen Q., Yu Z., Wang C., Jin S., Ding Y., Wu G. 2006. Dissolution of cellulose with ionic liquids and its application: a mini-review. Green Chemistry, 8(4), 325-327.

43. Zhu W., Li W., He Y., Duan T. 2015. In-situ biopreparation of biocompatible bacterial cellulose/ graphene oxide composites pellets. Applied Surface Science, 338, 22-26. 